\title{
European Federation for Medical Informatics (EFMI) - A Brief Outline
}

\author{
Alexander Hörbst' ${ }^{1}$, Alfred Winter ${ }^{2}$, Anne Moen ${ }^{3}$ \\ 1 EFMI Press and Information Officer, UMIT - University for Health Sciences, Medical Informatics and \\ Technology, Research Division for eHealth and Telemedicine, Austria \\ 2 EFMI Secretary, Leipzig University, Institute for Medical Informatics, Statistics and Epidemiology, \\ Leipzig, Germany \\ 3 EFMI President, University of Oslo, Institute for health and society, Faculty of Medicine, Norway
}

\section{Objectives}

The European Federation for Medical Informatics Association (EFMI) is the leading organisation in medical informatics in Europe as a federation of national societies in 30 countries. EFMI is organized as a non-profit organisation concerned with the theory and practice of Information Science and Technology within Health and Health Science in a European context.

The objectives when founded in 1976 were:

- To advance international co-operation and dissemination of information in Medical Informatics on a European basis;

- To promote high standards in the application of medical informatics;

- To promote research and development in medical informatics;

- To encourage high standards in education in medical informatics;

- To function as the autonomous European Regional Council of IMIA

\section{Activities and Governance}

All European countries are entitled to be represented in EFMI by a suitable Medical Informatics Society. The term medical informatics is used to include the whole spectrum of Health Informatics and all disciplines concerned with Health Informatics.

The organisation operates with a minimum of bureaucratic overhead. Each national society supports the federation by sending and paying for a representative to participate in the decisions of the Federation's Council, the membership assembly. Apart from the Council, an elected board consisting of nine members governs EFMI.

English has been adopted as the official language, although simultaneous translation is often provided for congresses in non-English speaking countries.

\section{Membership and Organization}

Currently, 28 countries have joined the Federation, including Armenia, Austria, Belgium, Bosnia and Herzegovina, Croatia, Czech Republic, Finland, France, Germany, Greece, Hungary, Iceland, Ireland, Israel, Moldova, The Netherlands, Norway, Poland, Romania, Russia, Serbia, Slovenia, Spain, Sweden, Switzerland, Turkey, Ukraine and United Kingdom. All representative societies in countries within the European Region of the WHO are entitled to apply for membership.

EFMI is also open for institutional membership. Typical institutions, which become EFMI members, include universities, research organisations, federations, industries and organisations. Currently, 12 organisations have become institutional members of EFMI: academic institutions, public or private organization, non-profit organization and 4 industrial and corporate organizations.

EFMI has a long tradition in working groups (WG) which are organising and supporting events and projects on a European basis but also worldwide in close co-operation with national and international WGs and institutions. EFMI does not offer personal membership except for the working groups.

\section{Congresses and Publications}

EFMI organizes two main series of conferences: the Special Topic Conferences (EFMI-STC) and Medical Informatics Europe (EFMI-MIE). In conjunction or independent of the main congress series, working groups contribute to organize topic specific workshops, tutorials and seminars, in the EFMI series and elsewhere.

As EFMI was founded in 1976 it celebrates its 40th anniversary this year. Therefore, several special events will be organized during the STC in Paris and MIE this year in Munich. This includes a workshop on focusing on European Medical Informatics History: People and Events (Mihalas et.al) given at STC2016, and a workshop "EFMI at 40: anticipating the future - appreciating the past (Hoerbst et.al)" as well as an EFMI-IMIA summit during MIE2016 in Munich.

\section{Medical Informatics Europe Conferences (MIE)}

So far 26 MIE conferences (Medical Informatics Europe) have been organised by the national members and EFMI, with up to more than 1000 participants. The conference includes per-reviewed presentations according to the type of paper as oral or poster presentation. Workshops and tutorials prepared or supported by EFMI working groups are an essential part of MIE conferences.

Medical Informatics Europe Conferences were held in Cambridge (1978), Berlin (1979), Toulouse (1981), Dublin (1982), Brussels (1984), Helsinki (1985), Rome (1987), Oslo (1988), Glasgow (1990), Vienna (1991), Jerusalem (1993), Lisbon (1994), Copenhagen (1996), Thessaloniki (1997), Ljubljana (1999), Hannover (2000), Budapest (2002) and St. Malo (2003), Geneva (2005), Maastricht (2006), Gothenburg (2008), Sarajevo (2009), Oslo (2011), Pisa (2012), Istanbul (2014), Madrid (2015) and Munich (2016).

\section{Special Topic Conferences (STC)}

STCs are conferences, specialized in current topics. Special Topic Conferences follow a successful concept including the following components:

- Organisation by a member society in combination with its annual meeting

- Topic defined to the needs of the member society 
- Relevant EFMI Working groups are actively involved

- Contributions mostly on invitation

- Small 2-day conference with $100+$ participants

STCs were so far organized in Bucharest (2001), Nicosia (2002), Rome (2003), Munich (2004), Timisoara (2006), Brijuni Island Croatia (2007), London (2008), Antalya (2009), Reykjavik (2010), Lasko (2011), Moscow (2012), Prague (2013) and Budapest (2014) and Paris (2016).

\section{Publications}

Publication of the conference proceedings of the EFMI conference series is done in close co-operation with IOS Press in its Medline indexed series "Health Technology and Informatics" for the last years. In recent time, EFMI has taken the decision to make their conference proceedings available through open-access. A selection of outstanding papers from the EFMI conferences are regularly published in Special Issues in the Journal Methods of Information in Medicine.

In addition to the already mentioned Journal Methods of Information in Medicine, EFMI has two further official journals, the European Journal of Biomedical Informatics and the International Journal of Medical Informatics.

\section{Communication}

Starting in 2013 the EFMI information system was completely revised and the old system replaced. Amongst other things, this included an adaption of the underlying information system concepts to the current needs of the EFMI members as well as a relaunch of the EFMI website. EFMI is currently running an up-to-date information system to support external and internal communication as well as the collaboration of EFMI members and working groups. The system is exclusively based on open-source solutions. In 2014 the decision was taken to start an EFMI facebook-site, which is currently extended and linked to other EFMI content.

Further information about EFMI and EFMI related activities can be obtained via EFMI's website: http://www.EFMI.org

Current EFMI Board Members

President:
Anne Moen
University of Oslo
Insitiute of Health and Society
Oslo, Norway
Vice President:
Lacramioara Stoicu-Tivadar
University Politehnica Timisoara
Department of Automation and Applied Informatics
Timisoara, Romania

Past President:

Patrick Weber

Nice Computing

Le Mont-sur-Lausanne, Switzerland

Secretary:

Alfred Winter

Leipzig University

Institute for Medical Informatics, Statistics and Epidemiology

Leipzig, Germany

Treasurer:

Ragnar Nordberg

Nordangsgatan 18

43169 Molndal

Sweden
Institutions Membership Officer:

Christion Lovis

University Hospitals of Geneva and University of Geneva

Division of Medical Information Sciences

Geneva, Switzerland

Press and Information Officer:

Alexander Hörbst

UMIT - Private University for Health Sciences, Medical

Informatics and Technology

Research Division for eHealth and Telemedicine

Hall in Tirol, Austria

Publication Officer:

Simon de Luisgnan

University of Surrey

Department of Health Care Management and Policy

Surrey, UK

Executive Officer:

Mira Hercigonia-Szekeres

University of Zagreb,

Faculty of Organization and Informatics

Varaždin, Croatia 